\title{
Reforma de sistemas de servicios de salud y equidad en América Latina y el Caribe: algunas lecciones de los años 80 y 90
}

\author{
Health systems reform and equity in Latin \\ America and the Caribbean: lessons from \\ the 1980s and 1990s
}

Celia Almei da 1

\footnotetext{
1 Departamento de

Administração e

Planejamento em Saúde,

Escola Nacional

de Saúde Pública,

Fundação Oswaldo Cruz.

Rua Leopoldo Bulhões 1480,

Rio de Janeiro, RJ

21041-210, Brasil.

calmeida@ensp.fiocruz.br
}

\begin{abstract}
This essay proposes a review of the issues of equity and reform in Latin America and the Caribbean in the context of changes in recent decades, emphasizing the discussi on of health systems reform. The economic, political, and social context prevailing in the critical 1970s extensi vel y favored budget cuts for public expenditures, cost containment, changes in the health sector power structure, and health services reorganization from an 'economicist', pragmatic, and restrictive perspective. An inventory of the Latin American economic and social situation is markedly negative, and efforts to recover from the damage done in the 1980s were largely unsuccessful in the 1990s. The reforms implemented in some paradigmatic countries (Chile, Colombia, Costa Rica, Argentina, and Brazil), in light of their specific characteristics, demonstrate the dissemination of a common agenda, adapted to the various national conditions. Some positive results of these processes were diluted in new problems caused by the reforms themselves, especially in countries with more radical adherence to the new reformist model; meanwhile, in the country where the public, universal system based on solidarity was most consolidated, the management changes have obtained the best results. However, overcoming inequalities is still a distant goal.

Key words Equity; Heal th System; Health Services; Health Sector Reform

Resumen Este ensayo propone una revisión dela cuestión equi dad y reformas en América Latina y el Caribe en el contexto de cambios de las dos últi mas décadas, dando énfasis a la discusi ón de la reforma de los sistemas de servicios de salud. La coyuntura económica, política y social de los críti cos años 70 fue ampliamente favorable a los cortes en el gasto público, sobre todo en el ámbito social, y a la reorganización de servicios de salud bajo una perspectiva economicista, pragmática y restrictiva. El balance de la situación económica y social latinoamericana es impactantemente negativo, e incluso los esfuerzos para recuperar los estragos de los años 80 no tuvieron mucho éxito en los 90. Las reformas implementadas en algunos países confirman la difusi ón de una agenda común, adaptada a las condiciones nacionales, siendo las opci ones más radicales de adhesión al nuevo model o reformista las que presentan peor impacto en términos de equidad. Algunos resultados posi ti vos de estos procesos se di luyen en los nuevos problemas suscitados por las propias reformas. La superación de las desi gualdades, sin embargo, todavía es una meta distante.

Palabras clave Equidad; Sistema de Salud; Servicios de Salud; Reforma del Sector Salud
\end{abstract}




\section{Introducción}

Desde los años 70 los análisis sobre las tendencias de desarrollo de los sistemas de servicios de salud enfatizaron los patrones del gasto sectorial en diversos países e identificaron presiones comunes que los impulsaban en una determinada dirección: el excesivo gasto con asistencia médica, en detrimento de otros aparentemente más importantes. Esta constatación fue interpretada como una inadecuada inversión sectorial, frente a los parcos resultados obtenidos en el desempeño de esos servicios, evidenciado, ya sea en los índices de morbimortalidad, o en la persistencia de las desigualdades sectoriales. En realidad, esta discusión es concomitante al inicio de cambios importantes en la dinámica del desarrollo mundial, donde la crisis económica forzó la reevaluación de las prioridades del gasto público, resaltando lo que Maxwell Ilamó creciente dilema de los policy makers - la coexistencia de una demanda infinita y de recursos finitos en el sector de salud (Maxwell, 1974). Este marco analítico se tornó rápidamente lugar común en la gran mayoría de los escritos de los analistas políticos sectoriales, de distintos credos y filiaciones metodológicas, muchos de ellos pertenecientes al ámbito económico, formulándose a partir de entonces las raíces de la "crisis en salud". Partiendo de diferentes presupuestos, distintos autores denunciaron la crisis de costos del sector; el excesivo y persuasivo poder médico; la demasiada, ineficiente e inefectiva intervención del Estado; en fin, la acción perjudicial e incontrolable del complejo médicoindustrial, que se habría desarrollado en el siglo XX bajo la égida del subsidio financiero estatal y del dominio hegemónico de los médicos. Además de eso, la reconocida mejoría de los indicadores de salud, como los de mortal idad, no puede ser atribuida exclusivamente a la acción de los servicios de salud; aún así la demanda por servicios había crecido de manera importante, ya sea por los cambios demográficos, o por el llamado imperativo tecnológico que guía el desarrollo de la medicina y de la asistencia médica. Sería necesario, por lo tanto, restringir el crecimiento del gasto sanitario, definiendo el monto de recursos que debe ser asignado a la salud (nivel macro) y reformar los sistemas de servicios, estableciendo prioridades de provisión e inversiones que fuesen más costo-efectivas y eficientes (nivel micro).

En la estela de esta discusión, a partir de los años 80 , la cuestión de la reforma del sector salud pasó a dominar el debate sectorial, y la literatura sobre el tema es abundante en práctica- mente todos los medios de publicación, impresos o electrónicos. Poco se discutió, sin embargo, sobre el contexto (económico, social y político) que da origen a esta ola contemporánea de reformas en la salud, así como sobre las referencias ideológicas que instruyen sus formulaciones o los principios y valores subyacentes a las diferentes estrategias de cambio. Esta ausencia no es ocasional o gratuita. En realidad, hay una tendencia a caracterizar estas reformas como procesos puramente técnicos, consecuencia natural de la "gran transformación" en la cual el mundo está envuelto hace más de dos décadas.

La evaluación de la "crisis de costos" en el sector está referida a los países centrales, cuyas reformas fueron fuertemente influenciadas por la crisis económica, colocando como imperativo la necesidad de controlar el déficit público y disminuir los gastos sanitarios, sobre todo su parte fiscal, en general, bastante alta, salvo la histórica excepción de los Estados Unidos. Las sociedades modernas y desarrolladas del mundo central, con raras excepciones, dedicaron sumas considerables a la estructuración de sistemas de servicios de salud universales, con un fuerte componente público, dirigidos a la producción y a la distribución de la asistencia médica. Esa dinámica fue impulsada en estrecha vinculación con la fiebre tecnológica de los "años dorados", configurando la llamada industria de la salud (o complejo médico-industrial), uno de los más prósperos ramos de la actividad económica en el mundo. Esto se tradujo en la creencia ampliamente difundida de que la disponibilidad y el uso cada vez mayor de los servicios médicos serían centrales, tanto para la salud individual como para la colectiva.

En muchos de los países avanzados, los cambios reformistas se vienen desarrollando a partir de negociaciones políticas complicadas, toda vez que el derecho a la salud como derecho de ciudadanía integra el elenco de beneficios posibilitados por las políticas sociales y compone el imaginario y la conciencia colectiva de la población. Como resultado, en la mayoría de estos países, las reformas se concentraron fundamentalmente en el área gerencial, no interfiriendo en las formas de financiamiento o en la estructura básica original del sistema de salud.

Ya para América Latina y el Caribe el diagnóstico de la crisis del sector es más tardío y, aunque también está relacionado con la crisis económica, los procesos de reforma en salud no provienen de la necesidad de disminuir el gasto, sino de la excesiva contracción impuesta por los ajustes económicos y por el escandaloso aumento de las desigualdades. Y, en muchos 
países, son concomitantes a complicadas transiciones políticas, que posibilitaron la vocalización de las demandas sociales y la reestructuración de los canales democráticos de participación de los intereses sectoriales, paralelamente a la exacerbación de conflictos y a la visualización de los diferentes proyectos de cambio. No obstante, el diagnóstico de la "crisis en salud" es semejante y los mismos modelos son difundidos y adaptados a la realidad regional.

Es importante señalar que la acumulación y la exacerbación de la "deuda social" en la región retratan siempre determinadas elecciones y opciones de políticas, realizadas por los gobernantes en coyunturas históricas específicas. O sea, a pesar de las condicionalidades de los acreedores internacionales y de la difusión de sus ideas, la adhesión a la nueva agenda de reforma no puede ser atribuida exclusivamente a estas variables.

La evolución histórica de América Latina y el Caribe está marcada por la constitución de Estados económicamente dependientes; sociedades altamente segmentadas, con considerables niveles de exclusión y marginalidad social; bases territoriales socialmente desintegradas; instituciones con baja capacidad de implementación de políticas y de regulación social; y estructuras de derechos de ciudadanía extremadamente frágiles y parciales. Estados con una “inserción subalterna en los mercados internacionales" y pautada por un endeudamiento progresi vo y perverso (Baltodano, 1997:56).

La intervención del Estado en la salud, aunque importante, en un primer momento vinculó las actividades médico-sanitarias (beneficencia pública, salubridad), de manera estrecha y centralizada, a los intereses económicos inmediatos y a las necesidades del comercio internacional. Y la transformación de la atención médica solamente se produjo después de los años 30 del siglo XX, incluyéndose la atención hospitalaria, aunque también de manera específica, esto es, privatizada o fuertemente subsidiada por el Estado y dirigida a grupos particulares. Esta estructuración fue coherente con la lógica de ciudadanía regulada (Santos, 1979) que orientó la forma de segmentación particularista que adquirió la política social en la región, funcionando como mecanismo "disfrazado" de transferencia de rentas, privilegiando a los sistemas corporativos de la sociedad y creando diferentes tipos de "ciudadanías" (Cavarozzi, 2001). Este modelo convivió también con variadas formas de control social de tipo oligárquico y de coerción estatal, por la fuerte presencia militar en el poder, sobre todo en el Cono Sur, que impidieron la formación de espa- cios públicos y el desarrollo de la capacidad de intervención de la sociedad en los asuntos que le atañen. Se agrega a este panorama la histórica influencia de los organismos internacionales en la formulación e implementación de políticas en la región (Malloy, 1993; Melo \& Costa, 1994). El resultado fue la implementación de políticas sociales poco inclusivas, ineficientes e inefectivas y el desarrollo de complejos médico-industriales desregulados, con alto grado de autonomía, que crecieron a la sombra del Estado o abiertamente subsidiados con recursos públicos.

Las reformas sectoriales contemporáneas han sido bastante variadas, dependiendo de la dinámica histórica de cada sociedad, de los actores involucrados en el proceso, del tipo de estructuración previa de los sistemas de salud y, principalmente, del valor que el beneficio social "atención a la salud" tiene en la sociedad bajo reformas.

Es necesario, por lo tanto, definir de quétipo de reformas estamos hablando. Partimos de la suposición que, de hecho, las reformas sectoriales en curso hace más de una década tienen profundas raíces en la dinámica de crisis y cambio global más amplio, pero se inscriben en un amplio movimiento que viene intentando revertir y reformular los valores y principios que orientaron la política de salud y la organización de sistemas de servicios tal como se desarrollaron y los conocimos en el siglo XX.

El hecho que debe ser destacado es que las coyunturas económica, política y social que siguieron a los críticos años 70 del siglo XX fueron ampliamente favorables a los recortes de gastos públicos, a la contención de costos, a cambios en la estructura de poder sectorial y a la reorganización de servicios de salud bajo una perspectiva economicista, pragmática y restrictiva. Los argumentos críticos al Estado de Bienestar Social, afirmados sobre la hegemonía neoliberal de las últimas décadas, fundamentaron la elaboración de una agenda reformista también para la salud, vinculada a la reforma del Estado, produciendo y difundiendo modelos que fueron divulgados como nuevos paradigmas de reestructuración de los sistemas de servicios de salud.

Este proceso cuestionó el derecho a la salud como un derecho humano o un beneficio social. La inspiración conservadora de esta agenda y su forma más radical limitan la reforma a la provisión de cuidados médicos individuales, sin tener en consideración el sistema de salud como un todo y las necesidades de salud de la población, ni relacionar el proceso de reforma sectorial con estrategias multisectoriales para 
la salud, con el objetivo de superar las desigualdades.

Asistimos así a la substitución de los valores de solidaridad e igualdad de oportunidad por los de un "individual ismo utilitarista radical" (Bobbio et al., 1993:689), más característico de siglos pasados que del fin del milenio; y del principio de "necesidades de salud o de servicios de salud" por el del "riesgo", monetarizado y definido según la posición social y económica del individuo. A partir de los años 80 , se pasó a creer en la posibilidad de armonizar los intereses particulares egoístas o de hacer coincidir la utilidad particular con la pública, aplicando a la salud, por analogía, los conceptos de mercado y de utilidad formulados por la economía.

En América Latina y el Caribe el aumento de los niveles de desigualdad en las dos últimas décadas, como consecuencia de las políticas de ajuste macroeconómico, referido por varios autores (Borón, 1995; Bustello, 1994; CEPAL, 1998; Hoeven \& Stewart, 1993), exacerbó el debate político y académico sobre la equidad, provocando reflexiones de las cuales emergen propuestas tales como la de transformación productiva con equidad (CEPAL, 1990, 1993) y de reformas sectoriales orientadas hacia la superación de las desigualdades (CEPAL, 1998, 2000; OMS, 1996; OPS/CEPAL, 1994). La cuestión de la equidad en salud volvió a ser colocada en el centro del debate académico y político, exigiendo revisiones teóricas y conceptuales y la búsqueda de instrumentos y métodos para evaluar y monitorear los resultados de las reformas.

Este ensayo pretende colaborar con esta discusión. Propone una breve revisión de la cuestión de la equidad y de la reforma en América Latina y el Caribe en el contexto de cambios de las dos últimas décadas del siglo XX, con énfasis en la discusión de las reformas de los sistemas de servicios de salud en la región. Primero presenta una síntesis del contexto de desarrollo económico y social en que operan estas reformas. Después discute el desarrollo de la política social y de la agenda de reformas en la región. A continuación analiza sintéticamente la implementación de la agenda reformista en el ámbito sectorial, señalando algunos resultados ya evidentes en algunos países. Y, finalmente, apunta algunos elementos críticos que comprenden la redefinición de la política de salud en el ámbito de las políticas sociales.
Panorama económico y social de la región en los años 80 y 90: un balance

De manera general, el balance de las décadas de los 80 y 90 en la región es desastroso y muy frustrante, con aspectos considerados positivos por algunos, pero prácticamente anulados por los efectos negativos concomitantes.

\section{Los ajustes económicos}

El proceso de reformas estructurales implementado en los años 80, orientado a substituir el desarrollismo anterior impulsado por el Estado, fue orientado hacia la apertura de las economías a la competencia externa y para dar mayor participación al sector privado. Este modelo se consolidó en la década de los 90, aunque avanzando a ritmo desigual en los distintos países, sea en las áreas comercial, financiera, laboral, de seguridad social o de reforma del Estado.

Los ajustes económicos implementados, centrados en políticas de estabilización monetaria ancladas en el cambio sobrevalorizado, si bien tuvieron éxito en el control de la inflación y en la reducción del déficit fiscal (con excepciones), desencadenaron un círculo vicioso impulsado por tasas de interés muy altas, en general por encima de la inflación, que estimularon la acumulación financiera privada e imposibilitaron la reanudación del crecimiento económico sostenido de la economía, exacerbando “Ios desequilibrios macroeconómicos, que aprisionan y paralizan las políticas públicas, forzando a los gobiernos a realizar sucesi vos e inútiles ajustes presupuestarios" (Fiori, 2001:12).

Los programas macroeconómicos implantados fueron viabilizados a partir de varios préstamos del Fondo Monetario Internacional a diferentes países de la región y, obviamente, la participación de los organismos multilaterales en estos procesos fue de inducción explícita, echándose mano a todos los instrumentos corrientes de regulación y control, además de sanciones específicas en caso de insubordinaciones o intentos unilaterales de decisión.

Contrariamente a lo que se predecía, en los años 90, la deuda externa de los países de la región continuó creciendo, entrando algunos al nuevo siglo seriamente endeudados, externa e internamente. El peso de este factor no es despreciable, principalmente porque las frágiles y desiguales "burbujas de crecimiento", que han caracterizado el desarrollo de las economías latinoamericanas, son fuertemente dependientes de la inversión externa y muy poco relacionadas con la capacidad interna de ahorro e inver- 
sión (Altimir, 1998; CEPAL, 2000). Por otro lado, la mayoría de estas inversiones externas son de carácter financiero especulativo, extremadamente volátiles, lo que inviabiliza la sostenibilidad de un proceso de crecimiento y desarrollo de más largo plazo. El flujo de estos capitales se produce por coyunturas internacionales particulares, que aumentan comparativamente las tasas de interés en la región latinoamericana, estimulando el desequilibrio entre importaciones y exportaciones y profundizando la recesión. Siendo así, el rápido crecimiento que se registró en algunos países en los primeros años de la década de los 90 se ha ido erosionando en la segunda mitad, con la única excepción de Costa Rica (CEPAL, 2000).

Ese puede ser considerado el escenario económico común para América Latina y el Caribe a inicios del siglo XXI, con raras excepciones, y la dinámica de inestabilidad del crecimiento económico y de las crisis financieras permanentes se acentuó de forma importante. La heterogeneidad estructural de los sectores productivos ha aumentado, con la implantación de más empresas de "clase mundial", en general, subsidiarias de transnacionales, y de pequeñas y medianas empresas que no han logrado adaptarse al nuevo contexto, teniendo como consecuencia el deterioro del mercado de trabajo y del ingreso, la erosión de la calidad del empleo, el aumento del desempleo abierto y de la informalidad y empeoramiento de la concentración de la renta, afectando la cohesión social y la gobernabilidad, con un concomitante aumento de las desigualdades y de la violencia (CEPAL, 2000). Las tasas de desempleo han mostrado una tendencia al alza, con aumento del desempleo urbano del 5,8\% a comienzos de la década de 90 al 8,7\% en 1999 (CEPAL, 2000).

\section{Pobreza y desigualdad}

Los ajustes habían contribuido, en los años 80, al aumento del número de pobres y de aquellos que vivían en situación de extrema pobreza (Altimir, 1998; Banco Mundial, 1993a, 1993b; Borón, 1995; Bustello, 1994; CEPAL, 1990, 1993; Filgueira \& Lombardi, 1995; OPS/ CEPAL, 1994), tendencia más acentuada en las áreas urbanas y metropolitanas. Esto no quiere decir que la pobreza rural se redujo, sino que la población rural disminuyó; mientras tanto, las condiciones más extremas de indigencia se manifestaban en las zonas rurales, con valores alrededor de un 37\% de la población total en la región (Filgueiras, 1997). A inicios de la década del 80, el número total de pobres alcanzaba 135,9 millo- nes de personas (40,5\%) de las cuales 62,4 millones (18,6\%) eran indigentes (CEPAL, 2000) y, a mediados de la década, estos números pasaron a ser 170,2 y 81,4 millones respectivamente ( $\mathrm{Fi}$ gueiras \& Lombardi, 1995). En los años 90, la proporción de los hogares en estado de pobreza era de $48,3 \%$ y aunque se redujo al $43,8 \%$ en 1999, el número absoluto de pobres aumentó entre 1990-1999 de 200,2 a 211,4 millones (CEPAL, 2000).

Paralelamente, aumentó de forma importante la vulnerabilidad económica de los sectores bajos y medios, como consecuencia de la mala distribución de renta, colocándolos más próximos de la línea de pobreza, sobre todo en las áreas metropolitanas, en todos los países. Vale la pena enfatizar que esta dinámica alcanza a los sectores medios ya consolidados, o en vías de formación, con especial impacto en los grupos con mayor nivel educacional (profesionales calificados y recién formados), debido, por un lado, a la dinámica de la reestructuración tecnológica y del desempleo, cíclica y selectiva, alcanzando más fuertemente a jóvenes y mujeres, y, por otro, a la composición de los nuevos puestos de trabajo, cuando existen - de baja calificación y productividad. Pero la vulnerabilidad de los pobres es más evidente debido a la exclusión tanto del proceso productivo como de los beneficios sociales de grandes segmentos de la población con baja capacidad de movilizar recursos individuales, frente a un abanico de opciones cada vez más estrecho (ya sea en el mercado, en el Estado o en la sociedad) y se crea, así, una estructura de pobreza social heterogénea (Filgueiras, 1998), para la cual la red de seguridad social tradicional (familia, vecindario, etc.) y los mecanismos o instrumentos sociales disponibles son insuficientes o inadecuados.

Se constata como rasgo común en todos los países una situación de "modernización excluyente" (Filgueira \& Lombardi, 1995), en el que el desarrollo social y la distribución de renta en general no corresponden a la riqueza relativa de cada país, medida en términos de PBI (Producto Bruto Interno) per capita, dato éste que gana importancia frente a la escandalosa concentración de renta y a los bajos salarios.

Cualquiera que sea el indicador de desigualdad que se adopte, con excepción del de Uruguay, se registró como tendencia general en la región, en las dos últimas décadas, la concentración de renta en los deciles más altos de la población, que aumentaron su participación en la renta total, con la consecuente caída de los 40\% inferiores (Figura 1). Los números indican que la distribución de renta históricamen- 
te desigual en la región empeoró mucho en la década de los 80 y continuó deteriorándose en los años 90, ostentando la más pronunciada disparidad entre ricos y pobres de todas las regiones del mundo, y Brasil lidera esta lista (CEPAL, 2000; Filgueiras, 1997; Kliksberg, 2000; Londoño \& Székely, 1997). La polarización aumenta más aún cuando se comparan los estratos más extremos de la estructura social, y las diferencias entre los países es expresiva (Figura 2).

La evolución de los grados de desigualdad medida por el Coeficiente de Gini (que varía de 0 a 1, donde 0 corresponde a la equidad total) indica que hubo una mejoría en la desigualdad de distribución de la renta de 1970 a 1980, que volvió a empeorar mucho de 1980 a 1990 y permaneció prácticamente inalterada en los años 90, a pesar de un mayor crecimiento económico. De hecho, al final de la década el promedio regional fue estimado en torno de 0,57 (Lodoño \& Szekély, 1997), mientras que el mundial es de 0,40 y el de los países desarrollados es de 0,30 (0,25 en los nórdicos escandinavos) (Kliks-

Figura 1

América Latina y el Caribe (17 países): participación en la inclusión total del 40\% de los hogares más pobres y del 10\% más ricos, 1990-1999a.

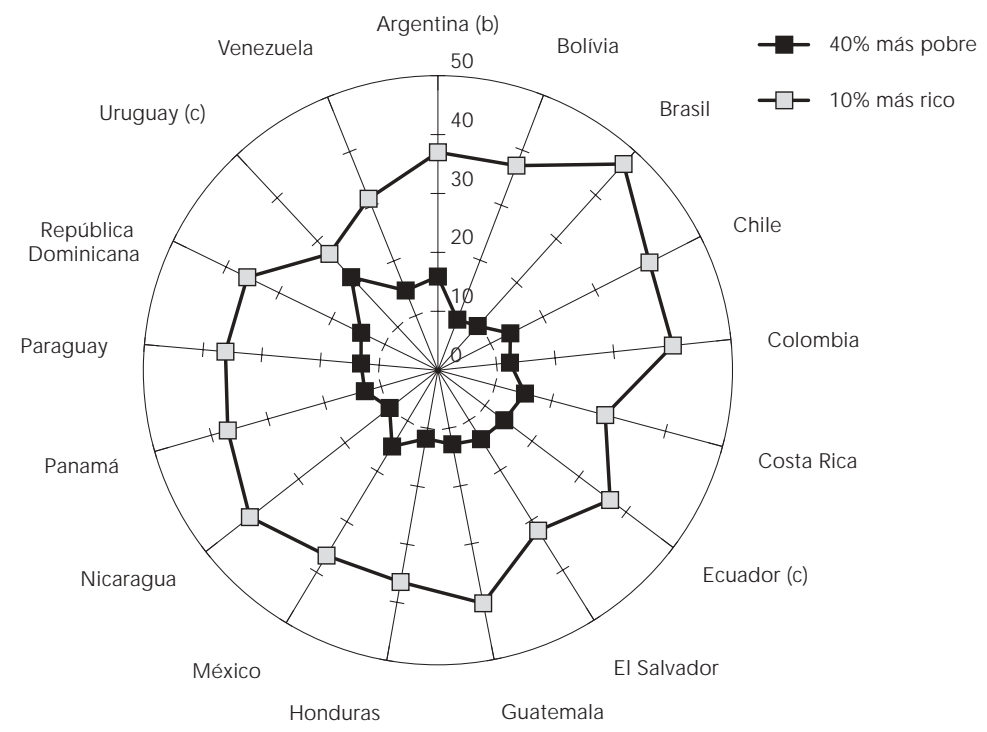

Fuente: CEPAL (2001:69) (sobre la base de tabulaciones especiales de las encuestas de hogares de los respectivos países; Cuadro II.1).

a Hogares del conjunto del país ordenados según su ingreso per cápita.

b Gran Buenos Aires

c Total Urbano berg, 2000).

Se puede afirmar que está siendo consolidada en América Latina una pirámide de ingreso un poco más estrecha en la base inferior, muy afinada en la parte alta y con una gran concentración de población alrededor de la línea de pobreza, como resultado directo de los ajustes implementados (Bustelo, 1994; Filgueiras, 1997).

En síntesis, en ningún país de la región se han reducido los niveles de desigual dad en relación con los imperantes desde los años 70 y para muchos la desigualdad es mayor que entonces. Y se observa una relación positiva entre el aumento de las desigualdades y el aumento de la pobreza; prueba de ello es que en los países menores en términos de población ese aumento fue mayor. Por otro lado, las desigualdades tienen un fuerte efecto negativo en la disminución de la pobreza, esto es, la reducción de la pobreza fue considerablemente inhibida por el aumento de las desigualdades, a pesar de las burbujas de crecimiento económico (CEPAL, 2000; Kliksberg, 2000; Székely, 2001).

El Índice de Desarrollo Humano - IDH (PNUD, 2001) de 26 países latinoamericanos confirma que la Región concentra las mayores disparidades mundiales, ocurriendo que el IDH del país mejor colocado, Barbados (IDH 0,864) es casi el doble del peor colocado, Haití (IDH $0,467)$, y su renta per capita es 10 veces superior (aún distando solamente algunos centenares de kilómetros entre las dos islas) (PNUD, 2001).

\section{La transición demográfica}

La población de América Latina y el Caribe representa cerca de $8,5 \%$ del total mundial y pasó de 165 millones de habitantes en 1950, a 509,2 millones a fines de los años 90. La fecundidad promedio en la región disminuyó del 3,9 en 1980 al 2,7 hijos por mujer en 1999. Aunque Ios niveles hayan bajado en todos los países, la diferencia entre los valores extremos no varió mucho, lo que quiere decir que la estructura de edad de la mayoría de los países sigue siendo predominantemente juvenil: en 1999, el 62,6\% de la población regional tenía entre 15-65 años de edad (cerca de 319 millones de personas), un $31,4 \%$ tenía menos de 15 años y el $6 \%$ estaba sobre los 65 años (CEPAL, 2001). Una síntesis histórica de los principales indicadores regionales se encuentra en la Tabla 1.

La tasa de crecimiento poblacional de la región se mantuvo en torno del 3\% al año hasta el final de los años 70, cuando comenzó a decaer, como consecuencia de la disminución de la tasa de fecundidad, llegó al 2,1\% en el período $1980-1990$ y a cerca del $1,7 \%$ en el período 
Polarización creciente del ingreso en América Latina y el Caribe, 1970-1995.

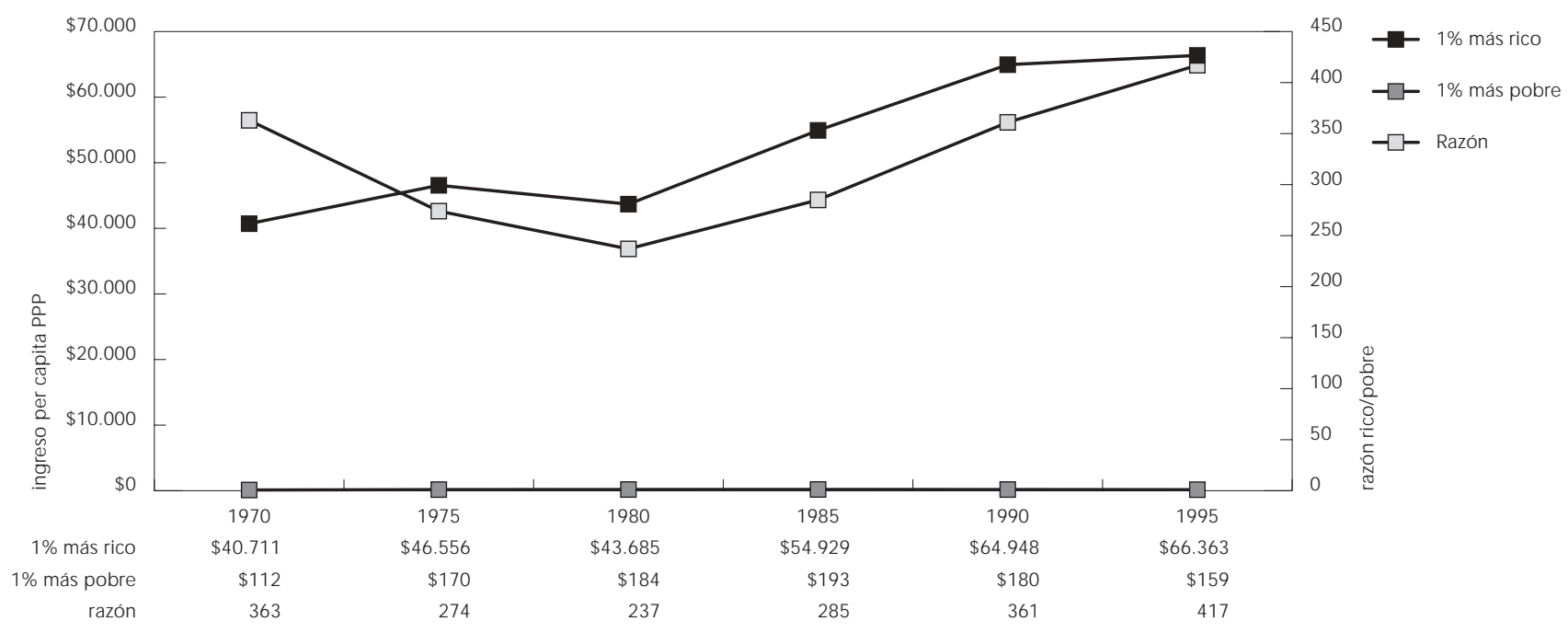

Fuente: Londoño \& Székely (1997).

1990-1999. Entretanto, la reproducción diferencial de diversos estratos sociales demuestra que la mayoría de los nacimientos continúa ocurriendo en los sectores más vulnerables, o sea, los pobres, indigentes y clases más bajas. El aumento del número de embarazos precoces (en adolescentes) y de madres solteras, así como el número de divorcios y separaciones (oficiales o no), la postergación del matrimonio y el número de mujeres jefe de familia, aluden a la desintegración de la idea de la familia tradicional y a la pérdida de la red primaria de soporte que debería ofrecer (Filgueiras, 1997).

La “transición demográfica”, esto es, el tránsito de altos hacia bajos índices de fecundidad y mortalidad, se consolidó, como en otras regiones, pero no se verificó el "bono demográfico", o sea, el crecimiento de la población en edad productiva y de la población económicamente activa en valores mayores que el crecimiento de la población no fue aprovechado en la región, principalmente por la escasa generación de empleo, sobre todo aquellos con altos niveles de productividad (Ocampo et al., 2001). Por otro lado, hubo un importante aumento de la participación de las mujeres en el mercado de trabajo (Tabla 1).

Se señala además, de manera general, el mayor envejecimiento de la población que, para algunos autores, es un proceso que se expre- sa de forma muy variada en la región y sólo como tendencia se puede prever cambios importantes en los perfiles epidemiológicos y en la demanda de servicios de salud (OPS, 1995, 1998). Para otros, la región estaría repitiendo la transición demográfica europea, pero con un ritmo diferente, pues estaría tomando mucho menos tiempo para mostrar una disminución significativa tanto en la mortalidad infantil como en la fecundidad. Siendo así, advierten que producirá efectos importantes en un período mucho más corto, lo que redundará en necesidades y demandas crecientes de servicios sociales, incluidos los de salud (Carvalho, 1998).

En realidad, la determinación de la magnitud de estas transiciones y de las demandas que serán generadas en este proceso es una tarea difícil, sea por la dispersión de los cambios sociales que tienen lugar dentro de cada país y entre países, sea por las diferencias en el comportamiento de las distintas clases y grupos sociales en cada sociedad, o por la tendencia contradictoria de estas transformaciones. De cualquier manera, indiscutiblemente es una transición "mixta que combina los efectos de una sociedad segmentada - tradicional y moderna" (Filgueira, 1997:138), agravada, empero, por los altos niveles de desigualdad. 
Tabla 1

Indicadores de América Latina y el Caribe, 1950-1999.

\begin{tabular}{|c|c|c|c|c|c|c|}
\hline Indicador & 1950 & 1960 & 1970 & 1980 & 1990 & 1999 \\
\hline Población (millones) & 165 & 210 & 275 & 360,3 & 432,4 & 509,2 \\
\hline Tasa promedio de crecimiento poblacional anual (\%) & - & 2,9 & 2,6 & 2,3 & 2,0 & 1,7 \\
\hline Tasa de fertilidad total (total de nacidos por mujer) & 5,9 & 6,0 & 5,0 & 3,9 & 3,4 & $\begin{array}{c}2,7 \\
(1998)\end{array}$ \\
\hline Población urbana (\%) & 42 & 50 & $\begin{array}{c}61,1 \\
(1975)^{a}\end{array}$ & 65 & - & 75 \\
\hline \multicolumn{7}{|l|}{ Población por grupos de edad (\%) } \\
\hline 0-14 años & 40 & 42 & 42 & 40 & 38,2 & 31,4 \\
\hline 15-64 años & - & - & - & 55,8 & - & 62,6 \\
\hline $65+$ años & - & - & - & 6,0 & - & 6,0 \\
\hline Población económicamente activa (total millones) & - & - & - & 130 & - & 219 \\
\hline $\begin{array}{l}\text { Crecimiento promedio anual de la población } \\
\text { económicamente activa (\%) }\end{array}$ & - & - & - & - & $\begin{array}{c}3,0 \\
(1980-1990)\end{array}$ & $\begin{array}{c}2,5 \\
(1990-1999)\end{array}$ \\
\hline Mujeres en la población económicamente activa (\%) & - & - & - & 28 & 35 & $41 b$ \\
\hline $\begin{array}{l}\text { Niños de } 10-14 \text { años en la fuerza de trabajo } \\
\text { (\% del grupo de edad) }\end{array}$ & - & - & - & - & 13 & 9 \\
\hline Esperanza de vida al nacer (años de vida) & $52 a$ & 57,1 & 61,2 & 65,4 & $66 \mathrm{~b}$ & $\begin{array}{c}69 b \\
\text { Hombres - } 66 \\
\text { Mujeres - } 72\end{array}$ \\
\hline Mortalidad infantil (por 1.000 nacidos vivos) & - & - & & 61 & $48 b$ & 31 \\
\hline Mortalidad entre menores de 5 años (por 1.000) & - & - & $125 a$ & 78 & - & $32 \mathrm{a}$ \\
\hline Prevalencia desnutrición infantil (\% de niños < 5 años) & - & - & - & - & - & $\begin{array}{c}8 \\
(1992-1998 c)\end{array}$ \\
\hline Acceso a agua potable (\% de la población) & - & - & - & $\begin{array}{c}73 \\
(1982)\end{array}$ & - & $\begin{array}{c}75 \\
(1995 c)\end{array}$ \\
\hline Acceso a saneamiento (\% de la población) & - & - & - & $\begin{array}{c}46 \\
(1982)\end{array}$ & - & $\begin{array}{c}68 \\
(1995 c)\end{array}$ \\
\hline Indicadores de Desarrollo Humano (IDH 2001) & - & - & - & - & - & 0,760 \\
\hline Tasa de analfabetos adultos ( $\%>15$ años) & - & - & - & - & - & $\begin{array}{c}12 \\
\text { Hombres - } 11 \\
\text { Mujeres - } 13\end{array}$ \\
\hline
\end{tabular}

Fuentes: Frenk (1999), Frenk et al. (1998), PNUD (2001), World Bank (2001), excepto indicaciones.

a PNUD (2001); b O campo et al. (2001); c Años más recientes para los datos estaban disponibles. 
El gasto social

Aunque la evolución de la crisis económica haya variado mucho de un país a otro, a lo largo de la década de los 80 el gasto social exhibió un deterioro generalizado, en términos absolutos, independientemente de la forma en que se utilice para medirlo y sólo en algunos pocos países hubo expansión relativa, con efectos asimétricos en los diferentes sectores (Bustello, 1994). La participación del gasto social en el gasto público total en general también sufrió una caída, lo que evidencia una política fiscal que privilegió las áreas no sociales. Por lo tanto, a diferencia de lo que ocurrió en Europa, en América Latina, en los años 80, el gasto social fue, sobre todo, un instrumento de ajuste fiscal, mientras que su función compensatoria con relación a los salarios fue secundaria (Cominetti, 1994). Así, en muchos casos, el declive en la inversión humana fue altamente "policyinduced" y no sólo causado por la recesión (Hoeven \& Stewart, 1993). Los sectores relativamente más vulnerables fueron vivienda y educación, pero también la seguridad social y la salud fueron alcanzadas de forma asimétrica. Los mayores cortes afectaron especialmente a las inversiones y no a los gastos corrientes, y el deterioro de la calidad de los servicios fue generalizado (Carciofi \& Beccaria, 1993, apud Bustelo,1994). La ausencia de cambios institucionales radicales - salvo reformas aisladas en algunos países - que permitiesen contrapesar la pérdida de recursos con una mayor eficiencia, llevó al empeoramiento acentuado tanto del acceso de la población a los servicios sociales administrados por el Estado como de la calidad de la atención al paciente.

Esta situación alcanzó particularmente a los grupos sociales más vulnerables, pues el impacto de la renta no monetaria sobre las familias es muy significativo en la región, ya que el gasto social representaba una fracción importante de la renta efectiva de los sectores más pobres, variando del $26 \%$ en Uruguay hasta un $50 \%$ en Chile y en Costa Rica (Bustello, 1994).

En contrapartida, y para intentar contrarrestar la tendencia anterior, en los años 90 el gasto público social ha aumentado considerablemente- del 10,4\% del PBI en 1990-1991 al 13,1\% en 1998-1999 (CEPAL, 2001) - pasando de un promedio de 360 dólares per capita anuales, al principio de la década, a 540 en 1999 (en US\$ de 1997). También aumentó la parte pública de ese gasto - del 42 al $48 \%$ del gasto público total - como resultado de una mayor prioridad fiscal. Ese crecimiento ha sido generalizado (con excepción de Honduras y Venezuela), pero no tuvo la misma magnitud en los distintos países: el aumento ha sido más rápido en los países de menores ingresos por habitante, donde dicho gasto suele ser más bajo, y en algunos hubo un aumento de más del 100\% (Colombia, Guatemala, Paraguay, Perú y República Dominicana). Ese incremento tampoco fue homogéneo a lo largo de la década; en la mayoría de los países el ritmo de expansión fue mayor durante el primer quinquenio (cerca de un $30 \%$ ) y el aumento fue mucho menor en el segundo (16\%) (CE$P A L, 2001)$. Sin embargo, esos aumentos no permitieron disminuir las pronunciadas diferencias entre los países, manteniéndose la enorme heterogeneidad, y en algunos los valores son todavía muy insuficientes, si se compara con el propio patrón regional.

Esa situación es más evidente en América Latina que en el Caribe, que históricamente ha tenido y continúa teniendo niveles de gasto social más elevados, pero con tendencias menos favorables a lo largo de los años 90 (CEPAL, 2000).

La cobertura de la seguridad social nunca fue significativa en la región, si se compara con los welfare europeos, y existe gran variación entre países. Argentina, Chile, Uruguay y Brasil fueron los pioneros en la creación de sus sistemas de protección social, pero también con coberturas diferenciadas y a inicios de la década de los 80 , cerca del $61 \%$ de la población de la región estaba cubierta por alguna forma de seguridad social, pero con gran diferencia entre estos países (OPS/ CEPAL, 1994), y los datos apuntan que el sector de la seguridad social fue el menos comprometido durante 1982-1989. Sin embargo, esas condiciones de protección social, tradicionalmente débiles, se han deteriorado en los años 90, incluso entre los asalariados urbanos formalmente afiliados a la seguridad social, que disminuyó del $67 \%$ al $62 \%$ entre 1990 y 1998 (OIT, 1999, apud CEPAL, 2000). Además, el número de cotizantes efectivos en los sistemas de previsión ha disminuido de forma pronunciada. Téngase presente que estas cifras representan una sobrestimación de la cobertura efectiva, por basarse en datos sobre afiliación en lugar de referirse a cotizantes activos; en segundo lugar, excluye a los trabajadores independientes y rurales, categorías generalmente desprotegidas. Las caídas en los niveles de empleo en el sector formal, combinadas con la desregulación del mercado de trabajo y el aumento del desempleo contribuyeron al mayor debilitamiento de los sistemas de protección social (en los países donde estaban más consolidados) y han impedido la expansión en los demás. Además de ello, algunos de los que habían avanzado en las cuestiones de 
welfare, como por ejemplo Chile, fueron los que adoptaron la opción de desmontaje más radical; mientras que otros, como Costa Rica, han soportado mejor la crisis, exactamente por el mantenimiento de las opciones anteriores de política social.

El mayor efecto redistributivo del gasto se observa si se excluye la seguridad social. El efecto redistributivo neto del gasto público social varía según el grupo social - la importancia relativa del gasto social es mucho mayor en los estratos de menores ingresos, representando cerca del $43 \%$ de su ingreso; en cambio en los estratos de mayores ingresos (quintiles cuarto y quinto) representa entre el 13 y el $7 \%$. Nótese que esa baja repercusión del gasto social en los ingresos del estrato más rico involucra un volumen cuantioso de recursos que en varios países supera o incluso duplica lo destinado a los hogares más pobres. Eso se explica por la cuantía de las transferencias de la seguridad social: en el estrato superior, más del $60 \%$ de las transferencias corresponden a la seguridad social, mientras que en el quintil más pobre representan sólo a cerca del $25 \%$ del total (CEPAL, 2001).

Se estima que, para el conjunto de la región, el $44 \%$ de la expansión del gasto social correspondió a incrementos en educación y saIud ( $28 \%$ y $16 \%$ respectivamente); el $51 \%$ a la ampliación del gasto en la seguridad social, principalmente pensiones y jubilación; y el 5\% restante a otros gastos, como vivienda, agua potable y saneamiento (CEPAL, 2000). En términos redistributivos, no fue igual en todos los países: en los de menor ingreso creció relativamente más el gasto en educación y salud (en general más progresivo), que representaron al $56 \%$ del total, mientras que la seguridad social sólo representó una quinta parte. En cambio, en los países de mayor gasto, la seguridad social captó alrededor de la mitad del incremento, y los mayores aumentos se registraron precisamente en los países en que ésta capta una fracción considerable de los recursos públicos - Argentina, Brasil, Chile y Uruguay. En lo referente a la salud, el incremento promedio regional ha sido de US\$28, a excepción de Chile, Colombia y Argentina (CEPAL, 2000).

Desigualdades en salud

También en la salud se observa en la región un agudo patrón de desigualdad. Aunque los promedios regionales y nacionales evidencien mejorías en algunos indicadores, principalmente cuando se comparan series históricas más largas, el refinamiento de los índices por niveles socioeconómicos, regiones geográficas, género, etnia y edad muestra amplios sectores de la población seriamente perjudicados, con diferentes estados de salud y con distintas oportunidades de acceso y utilización de los servicios de salud (OPS, 1999). Otra característica de este patrón regional es la gran diferencia de los indicadores entre los países, y entre regiones dentro de un mismo país.

La esperanza de vida media al nacer es de 68,7 años en la región (aumento importante con relación a los años 1950-1955, cuando era de 52 años), siendo inferior a los niveles de los países de la OECD (Organization for Economic Co-operation and Development - 77 años), pero superando el promedio mundial (67 años). Como extremos de esta realidad están, de un lado, Haití $(53,5)$ y Bolivia $(62)$ y, de outro, Costa Rica $(76,5)$, Cuba $(75,3)$ y Chile $(75)$ (CEPAL, 2001). Vale la pena mencionar que en 15 de los 10 países de la región el aumento quinquenal de la esperanza de vida fue menor en los períodos 1970-1975 y 1985-1990 y se observa una tendencia a la estabilización del indicador a partir de los años 90, o sea, es cada vez menor la tendencia al aumento de los años de vida de las poblaciones.

Distancias semejantes se observan en la mortalidad infantil. A pesar que los datos no están disponibles en todos los países para los mismos años, llama la atención la correlación entre las tasas de mortalidad infantil y el desarrollo social, sobre todo en los países con nivel de renta semejante. Entre 1980 y 1999 la tasa promedio de mortalidad infantil en la región bajó de 61 a 31/1.000 de nacidos vivos (NV) (CEPAL, 2001). Aunque la tasa promedio regional sea inferior al promedio mundial (54 por mil NV), continúa siendo mucho mayor que la de los países de altos ingresos y miembros de la OECD (cerca de un 9,4 por mil NV). Estas cifras disminuyeron prácticamente en todos los países, ya sea como resultado de políticas pasadas, sea porque fueron mantenidas acciones básicas y programas asistenciales específicos, o porque acciones en otras áreas se reflejaron positivamente impidiendo el empeoramiento de estos macro-indicadores en salud. No es por casualidad, por lo tanto, que Costa Rica (13), Cuba $(11,8)$ y Chile $(10)$ en general mantuvieran sus indicadores próximos a los de los países desarrollados (CEPAL, 2001).

Se observa además gran disparidad entre países, y también en un mismo país, al desagregar el promedio nacional de mortalidad infantil en diferentes grupos sociales (CEPAL/ CELADE/BID, 1996). Las diferencias son también bastante expresivas entre las zonas rura- 
les y urbanas, donde las tasas de mortalidad infantil tienden a ser mayores en el campo. Estas asimetrías se acentúan aún más en las poblaciones indígenas (CEPAL, 2000, 2001; Kliksberg, 1999).

En cuanto al perfil epidemiológico, las causas de muerte también han cambiado, presentando patrones mixtos donde conviven las muertes por enfermedades evitables - en los diversos grupos de edad - con aquellas producidas por enfermedades crónicas y degenerativas; dependiendo tanto del desarrollo económico-social como de la organización del sector salud, de la tasa de fecundidad, de las modificaciones en estructura de edad, del proceso de urbanización y de las condiciones de vida. Se registra también el recrudecimiento o empeoramiento de los contextos endémicos y epidémicos. Esto significa que los países enfrentan un cuadro complejo, con distintos tipos de problemas de salud y capacidades muy diferentes para resolverlos. Además, estos indicadores varían mucho de un país a otro e incluso dentro de un mismo país, entre diferentes regiones, grupos sociales, según distintos niveles de renta, raza, etnias, educación, género, entre otras variables (OPS, 1999). En general las desigualdades en salud son acumulativas, conforme se combinan y agregan de diversas maneras tales variables.

\section{El gasto nacional en salud}

No es tarea fácil compatibilizar las fuentes de datos existentes con relación al gasto nacional en salud en la región, pero algunas cifras son más o menos consensuales y es posible delimitar algunas tendencias.

Una de las características del gasto en servicios de salud en la región latinoamericana y del Caribe es su extrema heterogeneidad. Así, en 1999, el Gasto Nacional en Salud (GNS) promedio regional era de US\$ 498 per capita, sin embargo, mientras que este promedio en las Islas Vírgenes Británicas es casi dos veces y media y en Uruguay y Costa Rica es casi el doble, en Haití es cerca de $17 \%$ del promedio. Se destaca además que al rededor de seis países destinan menos de US\$200 per capi ta anuales para la salud; ya el gasto de Bolivia y Ecuador está muy próximo a los US\$100 (OPS, 2000).

El gasto regional en salud como porcentaje del PBI es considerado alto (7,5\% en 1995 y $7,3 \%$ en 1999), si se compara con el de las otras regiones "de renta media o baja" (alrededor del $5 \%$, siendo que para algunos autores, también es alto con relación a los resultados obtenidos (Schieber \& Maeda, 1999); entretanto, en 11 países de la región no alcanza el 5\% del PBI y en otros cinco está muy próximo de ese valor.

Nótese que la dinámica del gasto sanitario de la región latinoamericana ha presentado un comportamiento diferente al de los países desarrollados.

En Europa occidental la evolución del gasto tuvo tres períodos distintos: (a) rápido crecimiento en los años 1961-1970 en términos absolutos y con relación al PBI; (b) estabilización en los años 80, en respuesta a la crisis económica y al estancamiento de la inflación que llevó a la adopción de los controles macroeconómicos del gasto, vinculados al crecimiento del PBI y a políticas de contención de costos de la asistencia médica; y (c) el aumento en la primera mitad de los años 90, pari passu la severa recesión, y en la segunda mitad también, como reflejo de otros factores tales como la unificación alemana y el aumento del gasto en los países del sur, como España e Italia (Almeida, 1995; EOHCS/WHO, 1999). La parte pública del gasto también aumentó, con una ligera disminución en los últimos años de la década de los 90; y la parte privada disminuyó, con un pequeño aumento al final de la década.

El proceso en la región latinoamericana va en la vía opuesta: en los años 60 y 70 el gasto sanitario en general aumentó, aunque de forma heterogénea; en los años 80 disminuyó el promedio regional, como en 1985 cuando en algunos países esa caída fue del orden del 70\% de los valores de 1980 (World Bank, 1990); y, en la segunda mitad de la década hubo recuperación, con un ligero aumento a mediados de los años 90 y disminución en la segunda mitad (Tablas 2 y 3 ). Es preciso tener presente, sin embargo, que como el PBI disminuyó en ese mismo período, este aumento no significó más recursos para la salud en términos absolutos ( Tabla 3). La parte pública del gasto disminuyó en los años 80, aumentó un poco en el primer quinquenio de los 90, volviendo a decaer al final de la década; paralelamente, el gasto privado aumentó, declinando ligeramente al final de la década (Tablas 2 y 3 ). De una manera general, la mayor parte de este gasto está orientada a la atención curativa (72,6\% en 1995$)$, con apenas un $7 \%$ para prevención, el $12,1 \%$ para administración y un 8,3\% para otros gastos (infraestructura, insumos y formación de recursos humanos) (Molina et al., 2000).

La composición según sectores público y privado del gasto muestra que entre 1980-1999, el gasto privado fue el componente más importante del gasto total en salud: alrededor de $57 \%$ del gasto sanitario en toda la región (4,0\% del $\mathrm{PBI}$ ) en 1999, habiendo alcanzado un 58,5\% a 
mediados de la década. La parte pública de este gasto constituía en 1990 cerca de 43,4\% del gasto sanitario total, lo que representaba el 3,0\% del PBI. Este porcentaje era poco más de la mitad del promedio de los países de la Unión Europea (4,9\% del PBI) (OPS/ CEPAL, 1994). Durante los años 90 se observa una recuperación del gasto público, pero al final de la década, el aumento verificado (del 3,0\% al 3,4\%) aún continuaba bastante por debajo del promedio europeo y el porcentaje privado del gasto prácticamente se estabilizó; y el componente del gasto público atribuido a la seguridad social disminuyó de forma continua entre 1990-1999 (9,9\%), mientras que la participación del gobierno central aumentó un 10,8\% y la de los gobiernos locales apenas cerca del 1\%, con tendencia a la disminución al final de la década (Tabla 3). Las disparidades regionales en la composición público-privado también son expresivas: por un Iado está Cuba, Guyana y Costa Rica con baja participación del sector privado (17,4\%, 19,4\% y $24,5 \%$, respectivamente) y, por otro Guatemala y República Dominicana con una alta participación (73,6 y 71,1\%, respectivamente) (OPS, 2000).

El gasto de las familias - gasto directo (out of pocket) - es un componente importante del gasto privado - cerca del 39\%. Durante la década de los 90 se observa el desplazamiento del gasto privado directo al gasto con esquemas de medicina pre-pagada o seguros privados de salud. Este gasto directo está destinado principalmente a las consultas médicas y medicamentos, siendo que en estos últimos la mayor parte se realiza con medicamentos de marca (Molina et al., 2000). Esta situación ha aumentado la iniquidad en la región, pues las desigualdades en el gasto privado están estrechamente correlacionadas con las desigualdades de renta y, en general, están más concentradas que la distribución de la renta, pues en los países donde la participación privada es mayor (como Hondu-

\section{Tabla 2}

Indicadores de Gasto Nacional en Salud: OECD y América Latina, años 90.

\begin{tabular}{|c|c|c|c|c|c|c|}
\hline \multirow[t]{2}{*}{ Indicadores } & \multicolumn{3}{|c|}{ Unión Europea } & \multicolumn{3}{|c|}{ América Latina y el Caribe } \\
\hline & 19901 & 19972 & 19993 & 19903 & 19953,4 & 19993 \\
\hline Gasto Nacional en Salud (\% PBI) & 7,8 & 8,5 & 9,3 & 7,0 & 7,5 & 7,3 \\
\hline Público & 4,9 & 6,6 & - & 3,0 & 3,35 & 3,4 \\
\hline Privado & 2,9 & 1,9 & - & 4,0 & 4,3 & 3,9 \\
\hline \multicolumn{7}{|l|}{ Gasto Nacional Público en Salud $(\%)^{4}$} \\
\hline Total & 64,6 & 76,2 & 74,0 & 43,4 & 41,5 & 43,0 \\
\hline Gobierno central & - & - & - & 12,2 & 15,8 & 23,0 \\
\hline Gobiernos locales & - & - & - & 7,4 & 8,5 & 8,0 \\
\hline Seguro social & - & - & - & 23,9 & 17,2 & 14,0 \\
\hline \multicolumn{7}{|l|}{ Gasto Nacional Privado en Salud $(\%)^{4}$} \\
\hline Total & 35,4 & 23,8 & 26,0 & 56,6 & 58,5 & 57,0 \\
\hline Gasto indirecto (seguros/pre-pagas) & - & - & - & - & 19,5 & 18,0 \\
\hline $\begin{array}{l}\text { Gasto directo de las familias } \\
\text { (out-of-pocket) }\end{array}$ & - & - & - & - & 39,0 & 39,0 \\
\hline \multicolumn{7}{|l|}{ Gasto Nacional en Salud per capita (US\$) } \\
\hline Total & 1.620 & 1.771 & 2.063 & 133 & 240 & 498 \\
\hline Público & 1.010 & & & 58 & 102 & 214 \\
\hline Privado & 610 & & & 75 & 138 & 284 \\
\hline$\%$ de la población mundial5 & & 14,67 & 14,0 & 6,8 & 8,5 & 8,5 \\
\hline $\begin{array}{l}\text { PBI per capita promedio - PPA US } \$ 5,8 \\
\text { (en US\$ corrientes) } 6\end{array}$ & & 27.910 & 28.130 & $\begin{array}{c}- \\
(2.982)\end{array}$ & $\begin{array}{c}- \\
(3.640)\end{array}$ & $\begin{array}{c}6.880 \\
(3.640)\end{array}$ \\
\hline
\end{tabular}

Fuentes: 1 OPS (1995); 2 EOHCS (2000); 3 O PS (2000), excepto indicaciones; 4 Varias fuentes compiladas por Molina et al. (2000); 5,6 Banco Mundial (2001); 7 1996; 8 PPA = Paridad de poder adquisitivo (1990-1999), calculado por el Banco Mundial, año base 1996 y extrapolaciones para 1999 (Notas sobre las estadísticas en el Informe).

$\mathrm{PBI}=$ Producto Bruto Interno $\mathrm{OECD}=$ Organisation for Economic Co-O peration and Development. 
Tendencia del Gasto Nacional en Salud (GNS) como \% del Producto Bruto Interno (PBI)

en América Latina y el Caribe, 1980-2000.

\begin{tabular}{|c|c|c|c|c|c|}
\hline GNS/PBII & 1980 & 1985 & 1990 & 1995 & $1998-2000$ \\
\hline Público & 2,89 & 2,57 & 3,02 & 3,45 & 3,37 \\
\hline Federal & 1,26 & 1,16 & 1,16 & 1,41 & 1,52 \\
\hline Local & 0,44 & 0,46 & 0,57 & 0,95 & 0,82 \\
\hline Seguridad Social & 1,19 & 0,95 & 1,29 & 1,09 & 1,03 \\
\hline Privado & 3,20 & 3,21 & 3,99 & 4,04 & 3,93 \\
\hline Gasto directo de las familias & 3,20 & 3,17 & 3,92 & 2,91 & 2,85 \\
\hline Seguro privado/Planos & 0,02 & 0,04 & 0,07 & 1,13 & 1,08 \\
\hline Total GNS/PBI & 6,09 & 5,78 & 7,01 & 7,49 & 7,30 \\
\hline $\begin{array}{l}\text { PBI per capita promedio } \\
\text { América Latina y el Caribe } 2 \\
\text { (US\$ corrientes) }\end{array}$ & $\begin{array}{c}3.508,4 \\
(1970-2.852,4)\end{array}$ & 3.209 & 2.982 & $3.640^{3}$ & $3.680^{3}$ \\
\hline
\end{tabular}

Fuente: 1 O PS (2000); 2 Elaboración propia; 3 World Bank (2001).

ras) Ios quintiles más pobres destinan porcentajes mayores de su renta a la salud $(7,1 \%)$ que los quintiles más ricos. Lo inverso se verifica en los países con mayor participación pública en el gasto, como Costa Rica, donde los quintiles de menores rentas destinan $2,2 \%$ a la salud y este porcentaje aumenta a 4,5\% en los quintiles más ricos (Molina et al., 2000).

En síntesis, mientras que en la Unión Europea se observó en la década de los 90 un aumento del gasto sanitario nacional, con una disminución de la parte privada y un concomitante aumento del gasto público, en América Latina prácticamente se observó el proceso inverso, pues la recuperación de la parte pública del gasto fue relativamente modesta y el gasto privado se mantuvo alto, con un aumento del componente indirecto (esquemas de seguros privados y pre-pagos), a despecho de los indicadores socio-económicos lamentables y de las enormes desigualdades existentes.

Desigualdades en el sistema de servicios de salud

En lo que se refiere a los sistemas de servicios de salud, la caída en el gasto público llevó al deterioro, particularmente con relación a la inversión en infraestructura de los servicios financiados con recursos públicos, que son mayoritarios en la región. Los sistemas públicos no consiguieron superar los problemas de eficiencia, cobertura y calidad de la atención anteriores a la crisis, e incluso en ciertos casos se agravaron. En algunos países, principalmente aquellos que hicieron reformas importantes de los sistemas de salud (como Chile y Colombia), los servicios públicos han tenido que absorber mayor clientela entre los que, anteriormente, poseían cobertura de la seguridad social o que fueron excluidos de las organizaciones proveedoras privadas. Prácticas “informales” y formales de coparticipación del usuario pasaron a ser adoptadas en muchos países.

Las desigualdades en el acceso a los beneficios sociales en salud persisten no sólo entre diferentes grupos sociales, sino también entre regiones geográficas, en un mismo país, y entre países (OPS, 1995; OPS/CEPAL, 1994). En 1992 se estimaba que la magnitud del déficit de los sectores de saneamiento ambiental y de servicios de salud se traducía en la existencia de 130 millones de personas sin acceso a agua potable y 160 millones sin acceso permanente a los servicios de salud (OPS/ CEPAL, 1994). A fines de los años 90 se estimaba que un $25 \%$ de la población carece de acceso permanente a servicios básicos (cerca de 127 millones de personas); otro $25 \%$ no tiene acceso a agua potable y el 32\% vive en áreas sin saneamiento básico (en torno de 163 millones de personas) (CEPAL, 2001).

Un estudio realizado con seis países (Brasil, Ecuador, Guatemala, Jamaica, México y Perú) demuestra que estas desigualdades incluyen diferencias a favor de los ricos tanto en la oferta de servicios y profesionales, como en el estado de salud (independiente de la proxy de variables que se use para medirlas), o aún en el 
acceso a los servicios de salud, además de que el financiamiento también tiende a ser regresivo. Entretanto, Ias desigualdades en el estado de salud tienden a ser menos pronunciadas que las del acceso y de la utilización de los servicios; y las desigualdades en el acceso son menos pronunciadas que las desigual dades en el gasto privado. Además, las desigualdades son mayores en el acceso a cuidados preventivos que a la asistencia médica. Los grupos de renta más baja de la población enferman más y usan menos los servicios que los grupos de mejor renta. Se muestran también significativas las diferencias en el tipo de servicios utilizados por los diferentes grupos sociales: puestos y centros de salud y hospitales públicos son más utilizados por los pobres y grupos de baja renta; y los servicios privados son más utilizados por los grupos de renta más alta, con la excepción de los grandes hospitales públicos, generales, de emergencia o especializados (Suárez-Berenguela, 2000).

El mercado de servicios hospitalarios presenta un patrón complejo en la región, con enormes disparidades, y en algunos países (Argentina, Barbados, Cuba y Uruguay) el número de camas por habitantes es superior al de los países de la OECD. La relación entre el sector público y el privado está alterándose, con un rápido crecimiento de la infraestructura privada en la última década, a partir de una base de $20 \%$ a $40 \%$ de las camas disponibles.

En cuanto al consumo de medicamentos, también varía mucho de un país a otro: desde US\$ 80,00, en Argentina, a US\$ 7,00 per capita por año en la mayoría de los demás países (OPS/ CEPAL, 1994). La industria farmacéutica es dinámica en la región en lo que concierne a las innovaciones y a la elaboración de nuevos productos, sin embargo está concentrada en el ámbito curativo y de al to costo. Hasta hace muy poco, en la mayoría de los países los precios de Ios medicamentos estaban sujetos a control público. La desregulación de este mercado ha significado el aumento en los precios relativos y absolutos de los medicamentos, con considerable costo directo para las familias, dado que las instituciones públicas redujeron la cobertura de medicamentos distribuidos a los beneficiarios. Las acciones de vigilancia sanitaria en esta área son bastante débiles en la región, siendo frecuentes las denuncias de laboratorios ilegales y del uso de productos prohibidos en otros países. Por otro lado, el grado de automedicación en la región es uno de los más altos del mundo.

La mayoría de los países están descentralizando sus sistemas de salud hace más de una década, con mayor o menor dificultad, en muchos casos bajo una perspectiva desconcentradora del gasto del gobierno central, o incluso de privatizaciones sumarias, sin posibilitar que Ios niveles subnacionales de gobierno tengan condición de sostener o incrementar la atención a la salud de sus poblaciones. Se mencionan también innovaciones exitosas y procesos de descentralización con mejoría de la gerencia de los sistemas de salud a nivel local (Bossert et al., 2000; Levcovitz, et al., 2001).

\section{Política social y agenda de reforma}

Parafraseando el análisis elaborado por Melo (1998) para el Brasil, de una manera general podemos decir que algunos elementos comunes marcaron la pauta del desarrollo de la política social en Latinoamérica. Estos elementos señalan una trayectoria donde, en un primer momento, en los períodos corporativistas y populistas, la política social no fue formulada bajo la perspectiva de reducir las tasas de desigualdad; y con los regímenes militares, sobre todo en el período expansionista, fueron implementadas como si no fuesen políticas redistributivas, desplazándose hacia la cuestión del crecimiento versus distribución de renta. El debate sobre políticas de bienestar social prosperó en el contexto de la crítica a los regímenes dictatoriales, profundizando poco la discusión de la política social en sí, a no ser como "no política" o como la expresión material de la poca prioridad otorgada por los regímenes burocrático-autoritarios a los aspectos distributivos. El énfasis estaba puesto entonces en los efectos regresivos (perversos) de las políticas públicas no sociales y en la presuposición de la inexistencia de una política social (segunda mitad de los años 60 e inicio de los 70). Y, posteriormente (de la segunda mitad de los años 70 a la primera de los 80), en la crítica de la racionalidad que había incorporado la política social a una forma específica de acumulación - la constitución de complejos empresariales en torno a su dinámica (Melo, 1998).

Este debate se produce, no obstante, a escala planetaria a partir de la segunda mitad de los años 70, capitaneado por el Banco Mundial, que enfatiza la contraposición entre eficiencia (en la asignación) y equidad, retomando la cantilena crecimiento versus distribución, y pasando a difundir la fórmula "redistribución [solamente] con crecimiento". Se introduce también el abordaje de las "necesidades básicas" (Melo, 1998; Melo \& Costa, 1994). Al mismo tiempo que se reconocía la importancia de la interven- 
ción estatal en el sector social, se exacerbaba la crítica a su efectividad y a su capacidad resolutiva, en la que la cuestión central sería la incapacidad de las políticas de Estado para atender las necesidades básicas de la población objetivo, es decir, los más necesitados. El nuevo concepto que pasa a ser entonces difundido es el de "mala asignación" (mistargeting), o sea, el problema no era la irrelevancia del gasto social público sino su "mala utilización", toda vez que los beneficios eran inexpresivos frente a los costos asociados al mantenimiento de estructuras organizacionales gigantescas, caras e inefectivas.

El análisis se centró entonces en la forma de operacionalización de la política social y en su carácter burocrático, excluyente, ineficiente e ineficaz. La reforma administrativa y la descentralización (que además de "aproximar" los policy makers a las necesi dades de sus comunidades y poblaciones, podrían superar el "gigantismo burocrático") ocupan un lugar destacado en este debate. A partir de "reingenierías" institucionales y cambios "en las reglas de juego", influencia clara del paradigma neo-institucional ista, se espera obtener mayor eficiencia, equidad y la concomitante disminución de comportamientos depredadores y nocivos, utilizándose mecanismos que incentiven la competencia (Almeida, 1995, 2001; Almeida et al., 1999; Melo, 1998). El énfasis se puso, así, en la reforma de las leyes (Constitución) y de la arquitectura legal de los programas y políticas, entendidas como estructuras de subsidios e incentivos a ser redefinidas para modelar nuevos comportamientos.

Una vez más el Banco Mundial tomó la deIantera, ahora en el área social: al mismo tiempo que creó un fondo con el objetivo de aliviar las consecuencias económicas y sociales adversas de los programas de ajuste, anunciaba su entrada activa en los procesos de reformulación de las políticas sectoriales. El documento Financing Health Care: An Agenda for Reform (Banco Mundial, 1989) encuadraba el financiamiento de las reformas sanitarias en el elenco de condiciones negociadas en las bases de los ajustes económicos. En realidad, esa actuación más incisiva del Banco Mundial en el área de salud no era una acción aislada. Fue uno de los resultados de un cambio cualitativo en su actuación en la región, asumiendo una perspectiva más estratégica y de largo plazo, coherente con la "corrección de ruta" más amplia que orientó las prescripciones en el área económica (Fiori, 1993:137). Se adoptó entonces un enfoque más pragmático y explícitamente dirigido a prescripciones de reforma en el campo de
Ia salud. EI World Development Report: Investing in Health (World Bank, 1993c) hizo un análisis de los indicadores sanitarios disponibles en los diversos países, evaluados según parámetros estrictamente económicos, y estableció el escenario para un cambio en la política de salud.

La naturaleza dual de la cuestión salud para la región - como un fin en sí misma y como un medio para fomentar el desarrollo - ya había sido señalada por documentos producidos anteriormente por la CEPAL (1990), que subsidiaron el análisis del Banco, y la propuesta de política de salud que emergió del embate entre las agencias internacionales que actúan en la región, fue finalmente endosada también por la Organización Panamericana de la Salud (OPS, 1995; OPS/CEPAL, 1994).

Las condiciones de los acreedores internacionales pasaron entonces a incluir recomendaciones explícitas para la reforma de las políticas sociales, incluidas las de salud, abogando por una mejor utilización de los escasos recursos, que deberían ser dirigidos para intervenciones que disminuyesen la "carga de enfermedad" y fuesen comprobadamente costo-efectivas (World Bank, 1993c).

En trabajos anteriores analizé esta agenda y los respectivos modelos de reorganización de los sistemas de salud con mayores detalles. Para lo que nos interesa discutir aquí, basta retener que esta nueva agenda constituye un conjunto articulado de proposiciones (Almeida, 1995, 1999, 2001; Melo \& Costa, 1994): redefinición del mix público y privado y separación de funciones de financiamiento y provisión, con disminución de la intervención del Estado en la provisión de bienes y servicios y fortalecimiento de su poder regulador; direccionamiento de la esfera pública hacia los grupos sociales "más necesitados" (que no tengan condiciones para satisfacer sus necesidades a partir de la oferta de estos servicios en el mercado) y reorientación de la oferta pública, priorizando la prestación de servicios básicos y de bajo costo, lo que permitiría mayor cobertura y eficacia; descentralización funcional de las responsabilidades de prestación para los niveles subnacionales de gobierno; introducción de mecanismos competitivos (creándose cuasimercados o mercados regulados) y de contención, control y recuperación de costos, como forma de mejorar la eficiencia; y estímulo a la privatización, sobre todo con relación a la asistencia médica, con fomento del mercado privado de servicios y de la previsión social privada.

Las recomendaciones del Banco Mundial fueron fuertemente pautadas por los resulta- 
dos de un estudio de revisión - a Health Sector Priorities Review - desarrollado entre 1987 y 1993 (Murray \& López, 1994), que utilizó Ios DALYs (Disability Adjusted LifeYears) para mapear la carga global de la enfermedad y analizar diferentes intervenciones en términos de costo-efectividad. Este estudio indicó una gran variación de los costos por DALYs en cerca de 50 intervenciones y fue utilizado por el World Bank (1993c) para recomendar las reformas y nuevos indicadores. En otras palabras, la carga de enfermedad es estimada en términos de DALYs perdidos y el costo-efectividad de la intervención es evaluado por el costo ganado por DALYs. Esta combinación permitiría evaluar la carga de enfermedad evitada si las intervenciones fuesen implementadas, y solamente cuando la carga de enfermedad fuese grande y el costoefectividad alto, la intervención debería ser considerada una prioridad (World Bank, 1993c).

En la práctica, estas medidas se destinan a evaluar alternativas de decisión para las políticas sociales (ex-post e ex-ante), estableciendo relaciones entre costos y "beneficios", y la comparación de los resultados obtenidos por las diferentes formas de alcanzar determinados objetivos, jerarquizando opciones. Dicho de otra forma, significa aprovechar al máximo la efectividad de determinadas acciones maximizando el impacto al menor costo posible (Almeida, 2000a, 2000b). Varias críticas fueron publicadas, principalmente sobre la limitada concepción de salud (restringida a la asistencia médica); la poca validez de ejercicios globales para las realidades nacionales; la no consideración de la cuestión de la equidad, vista sólo como el logro de una alta expectativa de vida para todos los países, sin cualquier referencia a las desigualdades entre grupos sociales; y, lo más importante, la inadecuada utilización de metodologías económicas, básicamente centradas en medidas de eficiencia y costo-efectividad para captar necesidades de salud y definir prioridades, desconsiderando la validez de cualquier otro parámetro para la formulación de políticas (Paalman et al., 1998).

Más recientemente, la Organización Mundial de la Salud (OMS) también se adhirió a esta estrategia "metodológica", utilizándola para defender el "nuevo universalismo" (Frenk, 1999; WHO, 2000), es decir, ya que no es posible tener todo para todos, se debe definir lo "esencial" y que puede ser ofertado, enfatizando la evaluación del desempeño de los sistemas de servicios de salud como eje estructurador de la reforma sectorial (Murray \& Frenk, 1999). Otros nuevos indicadores fueron entonces creados (Disability-Adjusted Life Expectancy - DALE), además de índices compuestos utilizados para hacer un rank entre los países, a partir de una metodología ampliamente criticada en la literatura (Almeida et al., 2001; Blendon et al., 2001; Braveman et al., 2001, Jamison \& Sandbu, 2001; Navarro, 2000, sólo para citar algunos). De esta forma, la actual dirección de la OMS se adhiere explícitamente a lo que entiende como el mejor gerenciamiento del big business, esto es, la idea de que eficiencia y productividad son "metavalores" en la formulación e implementación de políticas y deben ser conseguidas a corto plazo y a cualquier precio, a partir de rígidos controles y estrategias normativas globales, a fin de satisfacer exigencias externas "supranacionales". Lo irónico de esta constatación es que "hace más de una década el sector de los grandes negocios está empleando enfoques más colaborativos y suaves y valorando las virtudes de la cooperación, empoderamiento e intercambio de conocimientos" (Lerer \& Matzopoulos, 2001:434). Aparentemente, la OMS habría adoptado lo peor de los dos mundos: lo peor del gerenciamiento del sector privado, tal como referido, y lo peor del sector público, por el autoritarismo y la falta de transparencia que han delineado la formulación de sus estrategias internacionales para el sector salud (Lerer $\&$ Matzopoulos, 2001)

En el mundo real, las reformas sectoriales se vienen desarrollando en diferentes momentos en los diversos países y con distintas características pero, de una manera general, incorporaron y reelaboraron las prescripciones de esa agenda mundial. El paradigma de la managed competition (competencia regulada), concebido en los Estados Unidos en los años 70 ha sido dominante (Almeida, 1995, 1996a, 1996b) y fue reactualizado recientemente para el contexto latinoamericano (Almeida, 2001; Almeida et al., 1999a). En su formulación original, pensada como una estrategia de organización de un sistema privado de servicios de salud, alía contención de costos y control de utilización, a partir de cambios en la estructura de subsidios e incentivos en el sector de servicios de salud, esto es, en la forma de asignación de recursos financieros, reorganizando la oferta y la demanda y redefiniendo los papeles de financiadores y proveedores de servicios, ya sean públicos o privados. Estos cambios se conseguirían con el fortalecimiento de la gerencia de los sistemas de salud y buscarían alcanzar mayor eficiencia y equidad, pues estarían centrados en la "elección del consumidor" lo que ordenaría y disciplinaría el mercado de servicios según los principios de calidad y efectividad. En el modelo preconizado para América Latina y 
el Caribe, Ilamado pluralismo estructurado (Frenk, 1994, 1998; Londoño, 1996; Londoño \& Frenk, 1995), se combina el seguro social (financiamiento público), con la separación de funciones e introducción de mecanismos competitivos (inspiración del Mercado Interno de la reforma inglesa), constituyéndose cuasimercados y creándose nuevas agencias (públicas y privadas) para la garantía del aseguramiento y de la provisión de servicios. Esta nueva estructuración de los sistemas sería capaz de producir resultados en salud más eficientes y, consecuentemente, de superar la iniquidad.

La revisión de las reformas en curso en la región demuestra que se han adoptado distintas modalidades de reforma de los sistemas de servicios de salud, pero existen elementos comunes en todos los procesos, introducidos en una perspectiva (teórica) de conciliar eficiencia y equidad. En general, han modificado las reglas de financiamiento y beneficios, y la participación de los agentes públicos y privados, separándose las funciones de regulación, provisión y financiamiento. Además, han estimulado una mayor presencia del sector privado en la gestión y provisión, instituido la libertad de elección de los afiliados y la competencia entre las entidades aseguradoras y entre las prestadoras de servicios, implantándose formas de cuasimercado en la provisión pública de servicios. La idea de seguro es dominante y existen diferencias importantes en las combinaciones entre seguro social (público y solidario) y seguros privados de riesgo con cotizaciones individuales, en la estructura de financiamiento, acceso, provisión de servicios y beneficios (Almeida, 1999; CEPAL, 2000; Sojo, 2001).

Básicamente, dos casos de reforma en la región son identificados como paradigmáticos, por la forma radical como han incorporado las innovaciones difundidas en la nueva agenda Chile y Colombia. Y otros tres son casos particulares por sus especificidades - Costa Rica, Argentina y Brasil. Los detalles de esas reformas son tratados en otros artículos de esta misma revista. Sin embargo, vale la pena Ilamar la atención hacia algunos puntos. Muy sucintamente, guardadas sus respectivas particularidades, las reformas implementadas confirman la difusión de una agenda común, adaptada a las condiciones nacionales. El primer caso Chile - es el pionero y el más radical, y se caracteriza por adoptar la privatización como eje central de la reforma, combinando seguros privados, competencia en el aseguramiento y segmentación de la estructura de financiamiento. El segundo es el más “innovador" - Colombia en la perspectiva de adhesión a la nueva agen- da contemporánea de reforma, implementando la competencia regulada en la administración de un seguro público universal y en la provisión de servicios, con previsión de integración progresiva de estructuras de financiamiento y beneficios segmentados. Argentina, a su vez, es ejemplo de los intentos de introducir cambios en un sistema universal, también mixto, pero fuertemente segmentado y controlado por grupos corporativos, debido a la importancia de la seguridad social en su estructuración. Mientras tanto, en Brasil la formulación del proceso de reforma estuvo vinculada a la transición democrática y es un intento de consolidar un sistema único de salud, público, universal y descentralizado, basado en la concepción de salud como derecho de ciudadanía y deber del Estado, aparentemente en una ruta contraria a la dinámica mundial. Y, Costa Rica es el país que mantuvo la estructura histórica del sistema de salud original, con seguro universal, administración y estructura financiera públicas, introduciendo mecanismos competitivos destinados a mejorar la eficiencia, eficacia y equidad del sistema, siendo la reforma que viene registrando mejores resultados.

Enfatizamos que algunos resultados positivos de estos procesos reformistas se diluyen en los nuevos problemas suscitados por las propias reformas, sobre todo en los países con opciones más radicales de adhesión a la nueva agenda; y en el país donde el sistema público, universal y solidario estaba más consolidado, los cambios gerenciales introducidos han obtenido mejores resultados (Sojo, 1998, 2001).

\section{Consideraciones finales}

El balance de la situación económica y social latinoamericana es impactantemente negativo, e incluso los esfuerzos para recuperar, Ios estragos de los años 80, por lo menos en parte, no tuvieron mucho éxito en los 90 . En lo que se refiere al sector salud, en términos generales, la situación no es animadora: se puede decir que en la última década del siglo $X X$, a pesar de las inmensas desigualdades regionales, el financiamiento público poco se alteró, al mismo tiempo que el gasto privado se mantuvo alto, con reducción del componente directo del gasto de las familias en favor del gasto con seguros privados y esquemas de prepago, de las empresas y otras organizaciones de la sociedad, además de que disminuyó la cobertura poblacional (con excepción de algunos países como Brasil y Colombia), empeoraron el acceso y la utilización de los servicios de salud y se deterioró 
considerablementela capacidad sectorial instalada, mayoritariamente pública, también con pocas y honrosas excepciones.

Se puede afirmar que, en algunos casos, las reformas implementadas fueron mucho más radicales que las de los países del Norte, abarcando varios ámbitos - desde el financiamento hasta la reorganización de los sistemas de servicios. Con esas reformas se esperaba "Iograr mayor transparencia y equilibrios financieros, mejorar la eficiencia en el uso de los recursose incorporar nuevos mecanismos para ampliar la cobertura de di chos sistemas y adaptarlos a los desafíos de la transición demográfica y epidemiológica de la población" (CEPAL, 2000:38). Sin embargo, su implementación ha implicado importantes conflictos con el principio de solidaridad y equidad, que tradicional mente guiaron la contribución y los beneficios en la salud, y la organización de los sistemas de servicios. Además, se aprobaron principios legales que al mismo tiempo institucionalizaron el derecho a la salud como beneficio social vinculado a la ciudadanía, formalizaron la cobertura universal y el compromiso con el principio de equidad (como Brasil y Colombia), pero la operacionalización de estos cambios ha aumentado la fragmentación y la segmentación de los sistemas de salud y no ha superado las desigualdades, aparte de dejar mucho a desear en términos de eficiencia.

A pesar que la implementación de estos model os de reforma exige fuerte capacidad de regulación y desarrollo institucional, de una manera general la correspondiente reforma de las entidades públicas no se llevó a cabo como era necesario para garantizar los objetivos planteados en las premisas reformadoras. Por otro lado, el desarrollo de esas capacidades fue sumamente dificultado por el estrés fiscal y por la destrucción de las instituciones públicas.

En síntesis, el dilema genuino entre la administración de recursos escasos (eficiencia) y la superación de las desigualdades (justicia social) fue extremadamente exacerbado en las últimas décadas, cuando la creencia en la posibilidad de equilibrar estos dos parámetros fue cuestionada y las políticas neoliberales enfatizaron el individualismo y vincularon la política social estrictamente al cálculo económico, agudizando el conflicto entre valores y revigorizando la contabilidad ética que le es subyacente (Santos, 1998). Y este dilema es especialmente importante en la región latinoamericana, toda vez que las condicionalidades externas han encontrado fuerte aceptación nacional y la experimentación ha proliferado de forma acrítica.
Sería necesario, por lo tanto, retomar la discusión de las políticas sociales bajo otra perspectiva, como por ejemplo, sugiere Santos (1998: 51), al definirlas como meta-política, esto es, como la "matriz de principios que justifica el ordenamiento de cualesquier otras políticas". Esto significa revigorizar la discusión de los principios y valores que le son subyacentes y definir principios de justicia coherentes y consistentes en los cuales apoyarse, aparte de operacionalizarlos de forma efectiva. Resta, por tanto, incluir en esta ecuación la negociación política.

Además, aunque sea necesario elegir alternativas y definir prioridades para la actuación del Estado en el sector, la solución no está en “transferir el problema del ámbi to político, significativamente indeterminado y al tamente vaIorativo, para el universo del discurso lógico" (técnico) (Santos, 1998:40), supuestamente neutro y que obedece a reglas racionalmente irrecusables, como se viene haciendo. Esta dinámica requiere el ordenamiento de preferencias, que implica la introducción de condiciones (nacionales y locales) impuestas por la realidad, donde el discurso y la retórica de los que deciden y de sus críticos se concretizan. Y este ordenamiento de preferencias no puede ser lógicamente deducido, lo que significa que no es posible resolverlo a partir únicamente de la lógica científica (técnica). En otras palabras, es preciso recordar que se está tratando de decisiones de políticas que presuponen la distribución de cuotas distintas de beneficios y sacrificios entre los individuos de una sociedad, que aseguren la minimización del conflicto social y algún orden social, lo que requiere procedimientos adecuados. La cuestión substantiva, por tanto, es definir cuál sería la "distribución justa dela relación sacrificio/beneficio entrelos individuos de la sociedad" (Santos, 1998:51). Recae, así, en la lógica política del "cálculo del disenso", esto es, cuál es el consenso posible o el disenso soportable en determinada sociedad, en determinada coyuntura. Se refiere, en última instancia, al grado de desigual dad (y de conflicto) que una sociedad está dispuesta (o consigue) soportar.

En la coyuntura actual de reformas sectoriales, el principio de equidad, presente en la agenda reformadora, frecuentemente está condicionado a los objetivos de eficiencia, sometida a los "límites de caja", y de costo-efectividad, que a su vez, no incluye el análisis de los objetivos de determinada política y excluye explícitamente la valoración de los fines que la justifican, cuya definición e implementación pertenecen al campo político y no al análisis técnico. En otras palabras, aunque sea deseable 
y necesario que las acciones en salud sean más efectivas y eficientes, la cuestión de las diferentes necesidades de distintos grupos poblacionales no se resuelve solamente con esta "cuantificación de la política". Ni tampoco con la disminución de la intervención estatal y del financiamiento público a los Ilamados mínimos básicos, traducidos en las políticas de focalización (entre los más pobres) y de privatización, pregonadas como más equitativas, lo que además no se verifica en la práctica. En realidad, se intenta, de esta forma, redefinir la función distributiva del Estado en el terreno de los servicios de salud, restringiéndose substancialmente el carácter de la política de salud como política social.

El desarrollo técnico innovador es importante, sin duda, pero tiene que llevar en consideración la realidad concreta donde la innovación se realiza, identificar los problemas precozmente y buscar las soluciones para superarlos, ámbito donde lo técnico y lo político se en-

\section{Agradecimiento}

Este ensayo es parte del trabajo de investigación desarrollado en el ámbito del Programa Equity-oriented Health Policy Analysis in Latin America, implementado por la Red de Investigación en Sistemas y Servicios de Salud en el Cono Sur de América Latina, en cooperación con la Escola Nacional de Saúde Pública, Fundação Oswaldo Cruz (ENSP/FIOCRUZ), financiado por el Internacional Development Research Center (IDRC), de Canadá. Agradecemos la colaboración de Maria Inês Vaz Genoese, asistente de programas de la Red, y de Eliane dos Santos Oliveira, investigadora de la ENSP/FIOCRUZ; y de Cesar Vieira y Ruben Suarez, de la División de Salud y Desarrollo Humano de la Organización Panamericana de la Salud, Washington, por el apoyo en la colecta y en la organización de los datos. Obviamente el análisis presentado es de exclusiva responsabilidad de la autora. Agradecemos también el trabajo de revisión del español realizado por Carmen Phang Romero, Walter I panaqué Casas y Maria Eliana Labra. trelazan de forma inexorable. Esto quiere decir también que es fundamental minimizar la incertidumbre radical subyacente a las elecciones hechas e inherentes al juego político, Io que presupone la reconstrucción de la capacidad de previsión, de planificación y de implementación de políticas, estimulando la innovación responsable y la creatividad, perfeccionando instrumentos de análisis y modificando las rutinas de comportamiento. Además de ello, es preciso superar el "cinismo" de las certezas, que encubre la duda y la incertidumbre inherentes a cualquier cambio.

Finalmente, las dificultades de evaluación de la eficacia y de la efectividad de la política social son innumerables y no se pretende minimizar o descalificar a priori los esfuerzos que están siendo realizados en ese sentido. La verificación debe ser permanentemente reinventada y es importante mantener viva la creatividad. Pero, es crucial revitalizar la capacidad de análisis crítico.

\section{Referencias}

ALMEIDA, C. M., 1995. As Reformas Sanitárias nos Anos 80: Crise ou Transição? Tese de Doutorado, Rio de Janeiro: Escola Nacional de Saúde Pública, Fundação Oswaldo Cruz.

ALMEIDA, C. M., 1996a. Os modelos de reforma sanitária dos anos 80: Uma análise crítica. SaúdeeSociedade, 5:3-57.

ALMEIDA, C. M., 1996b. Novos modelos de reforma sanitária: Bases conceituais e experiências de mudança. In: Política de Saúde e Inovação Institucional (N. R. Costa, \&J. M. Ribeiro, org.), pp. 6998, Rio de Janeiro: Editora Fiocruz.

ALMEIDA, C. M., 1999. Reforma do Estado e reforma de sistemas de saúde: Experiências internacionais e tendências de mudança. Ciência \& Saúde Coletiva, 4:263-286.

ALMEIDA, C. M., 2000a. Saúde nas reformas contemporâneas. In: Saúde, EqüidadeeGênero (A. M. Costa, E. Merchán-Hamann \& D. Tajer, org.), pp. 61-93, Brasília: Editora Universidade de Brasília/ Asociación Latinoamericana/ Rio de Janeiro: ABRASCO.

ALMEIDA, C. M., 2000b. Saúde e eqüidade nas reformas contemporâneas. Saúde em Debate, 24:6-21.

ALMEIDA, C. M., 2001. Reforma del Estado y reforma de sistemas de salud. Cuadernos Médico-Sociales, 79:27-58.

ALMEIDA, C. M.; TRAVASSOS, C.; PORTO, S. \& WARGAS, T. B. F., 1999. A Reforma Sanitária Brasileira: Em Busca da Eqüidade, Washington, DC: Organização Pan-Americana da Saúde. 
ALMEIDA, C. M.; BRAVEMAN, P.; MARTHE, R. G.; SZWARCWALD, C. L.; RIBEIRO, J. M.; MIGLIONICO, A.; MILAR, J.; PORTO, S.; COSTA, N. R.; ORTÚN, V.; SEGALL, M.; TRAVASSOS, C.; U GÁ, M. A; VALENTE, J. \& VIACAVA, F., 2001. Methodological concerns and recommendations on policy consequences of the World Health Report 2000. Lancet, 357:1692-1697.

ALTIMIR, O., 1998. Desigualdad, empleo y pobreza en América Latina: Efectos del ajuste y del cambio en el estilo de desarrollo. In: Pobreza y Desigualdad en América Latina (V. Tokman \& G. O'Donnel, org.), pp. 23-54, Buenos Aires/Barcelona/ México, DF: Paidós.

BALTODANO, A. P., 1997. Estado, soberanía y políticas públicas en América Latina y Estado, ciudadania y política social en América Latina. In: Globalización, Ciudadanía y Política Social en América Latina: Tensi ones y Contradicciones (A. P. Baltodano, org.), pp. 16-66, Caracas: Nueva Sociedad.

BANCO MUNDIAL, 1989. El financiamiento de los servicios de salud en los países en desarrollo. Una agenda para la reforma. In: Economia de la Salud - Perspectivas para la América Latina (Organización Panamericana de la Salud \& Organización Mundial de Salud, org.), pp. 145-159, Publicación Científica 517. Washington, DC: Organización Panamericana de la Salud/Organización Mundial de Salud.

BLENDON, R. J.; KIM, M. \& BENSON, J., 2001. The public versus the World Health Organization on health system performance. Health Affairs, 20:10-20.

BOBBIO, N.; MATTEUCCI, N. \& PASQUINO, G., 1993. Dicionário de Política, v. 2. 5a Ed. Brasília: Editora da Universidade de Brasília.

BORON, A., 1995. Democracia e reforma social na América Latina: Reflexões a propósito da experiência européia. In: Estado, Capitalismo e Democracia na América Latina. (A. Borón, org.), pp. 153-184, Rio de Janeiro: Editora Paz eTerra.

BOSSERT, T.; LARRAÑAGA, O. \& MEIR, F. R., 2000. Decentralization of the health systems in Latin America. Revista Panamericana deSalud Pública, 8:8492.

BRAVEMAN, P.; STARFIELD, B. \& GEIGER, H. J., 2001. World Health Report 2000: How it removes equity from the agenda for public health monitoring and policy. BMJ, 323:678-680.

BUSTELLO, E., 1994. Hood Robin: Ajuste e equidade na América Latina. Planejamento e Políticas Públicas, 11:4-48.

CARVALHO, J. A. M., 1998. La demografía de la pobreza y el bienestar en América Latina. Desafíos y oportunidades. In: Pobreza y Desigualdad en América Latina (V. Tokman \& G. O’Donnel, org.), pp. 69-96, Buenos Aires/Barcelona/ México, DF: Paidós.

CAVAROZZI, M., 2001. Dela Convivencia a la Desintegración: Ciudadanías y Políticas Sociales en Amé rica Latina. Rio de Janeiro: Escola Nacional de Saúde Pública, Fundação Oswaldo Cruz. (mimeo.)

CEPAL (Comisión Económica para América Latina y el Caribe), 1990. Transformación Productiva con Equidad - La Tarea Prioritaria del Desarrollo de América Latina y el Caribe en los Años Noventa. Santiago de Chile: Naciones Unidas/CEPAL.
CEPAL (Comisión Económica para América Latina y el Caribe), 1993. Panorama Social de América Latina. Santiago de Chile: CEPAL.

CEPAL (Comisión Económica para América Latina y el Caribe), 1998. Panorama Social de América Latina, 1997. Santiago de Chile: Naciones Unidas/ CEPAL.

CEPAL (Comisión Económica para América Latina y el Caribe), 2000. Equidad, Desarrollo y Ciudadanía. Santiago de Chile: Naciones Unidas/CEPAL.

CEPAL (Comisión Económica para América Latina y el Caribe), 2001. Panorama Social de América Latina y el Caribe, 2000-2001. Santiago de Chile: Naciones Unidas/CEPAL.

CEPAL (Comisión Económica para América Latina y el Caribe)/ CELADE (Centro Latinoamericano de Demografía)/BID (Banco Interamericano de Desarrollo), 1996. Impactos de las Tendencias Demográficas sobre los Sectores Social es en América Latina: Contribución al Diseño de Políticas y Programas. Santiago de Chile: CEPAL.

COMINETTI, R., 1994. Ajuste fiscal y gasto social. Revista de la CEPAL, 54:47-60.

EOHCS (European Observatory on Health Care Systems)/WHO (World Health Organization), 1999. Health Care Systems in Transition - United Kingdom. Copenhagen: EOHCS/WHO.

FILGUEIRA, C. \& LOMBARDI, M., 1995. Social policy in Latin America. In: Social Policy in a Global Society (D. Morales-Gómez \& M. Torres, ed.), pp. 123170, Otawa: International Development Research Center.

FILGUEIRAS, C. H., 1997. Bienestar, ciudadanía, y vulnerabilidad en Latinoamérica. In: Globalización, Ciudadanía y Política Social en América Latina: Tensiones y Contradicciones (A. P. Baltodano, org.), pp. 123-147, Caracas: Nueva Sociedad.

FILGUEIRAS, C. H., 1998. Bienestar y ciudadanía. Viejas y nuevas vulnerabilidades. In: Pobreza y Desigualdad en América Latina (V. Tokman \& G. O'Donnel, org.), pp. 147-170, Buenos Aires/Barcelona/ México, DF: Paidós.

FIORI, J. L., 1993. Sobre a crise contemporânea: Uma nota perplexa. Síntese- Nova Fase, 20:387-402.

FIORI, J. L., 2001. 60 Lições dos Anos 90 - Uma Década de Neoliberalismo. Rio de Janeiro: Editora Record.

FRENK, J., 1994. Dimensions of health system reform. Health Policy, 27:19-34.

FRENK, J., 1999. Building on the Legacy: Primary Health Careand the New Policy Directions at WHO. Chicago: American Public Health Association. (mimeo.)

FRENK, J.; LONDOÑO, J. C.; KNAU L, F. \& LOZANO, R., 1998. Los sistemas de salud latinoamericano en transición: Una visión para el futuro. In: Atención a la Salud en América Latina y el Caribeen el Siglo XXI (C. Bezold, J. Frenk \& S. McCarthy, org.), pp. 119-156, México, DF: Institute for Alternatives Futures/Fundación Mexicana para la Salud/SmithKline Beecham Pharmaceuticals.

JAMISON, D. T. \& SANDBU, M. E., 2001. WHO ranking of health system peformance. Science, 293:15951596.

KLIKSBERG, B., 2000. Desi gualdades na América Latina - O Debate Adiado. São Paulo: Cortez Editora/ Brasília: Organização das Nações Unidas para a 
Educação, a Ciência e a Cultura.

LERER, L. \& MATZOPOULOS, R., 2001. The worst of both worlds: The management reform of theWorld Health Organization. International Journal of Health Services, 31:415-438.

LONDOÑO, J. L., 1996. Estructurando pluralismo en los servicios de salud. La experiencia colombiana. Revista deAnálisis Económico, 11:37-60.

LONDOÑO, J. L. \& FRENK, J., 1995. Structured Pluralism: Towards a New Model for Health System Reform in Latin America. Washington, DC: Technical Department for Latin America and the Caribbean, World Bank.

LONDOÑO, J. L. \& SZÉKELY, M., 1997. Persistent Poverty and Excess Inequality: Latin America, 1970-1995. Working Paper Series 357. Washington, DC: Inter-American Development Bank.

MALLOY, J., 1993. Statecraft, social policy, and governance in Latin America. Governance: An International Journal of Policy and Administration, 6: 220-274.

MAXWELL, R. 1974. The Growing Dilemma. New York: McKinsey.

MELO, M. A., 1998. As sete vidas da agenda pública brasileira. In: Avaliação das Políticas Sociais: Uma Questão em Debate (E. M. Rico, org.), pp. 11-28. São Paulo: Cortez Editora/Instituto de Estudos Especiais, Pontificia Universidade Católica de São Paulo.

MELO, N. R. \& COSTA, M. A., 1994. Desenvolvimento sustentável, ajuste estrutural e política social: As estratégias da OMS/OPS e do Banco Mundial para a atenção à saúde. Planejamento e Políticas Públicas, 11:50-108.

MOLINA, R.; PINTO, M.; HENDERSON, P. \& VIEIRA, C., 2000. Gasto y financiamiento en salud: Situación y tendencias. Revista Panamericana de Salud Pública, 8:71-83.

MURRAY, C. J. L. \& FRENK, J., 1999. A WHO framework for assessing the performance of health systems. Bulletin of theWorld Health Organization, 78:717-731.

MURRAY, C. J. L. \& LOPEZ, A. D., 1994. Global Comparative Assessment in the Health Sector. Geneva: World Health Organization.

NAVARRO, V., 2000. Assessment of the World Health Report 2000. Lancet, 356:1598-1601.

OCAM PO, J. A.; BAJRAJ, R. \& MARTIN, J., 2001. Una Década de Luces y Sombras: América Latina y el Caribe en los Años Noventa. Santiago de Chile: Comisión Económica para América Latina y el Caribe/ Alfaomega.

OPS (Organización Panamericana de la Salud), 1995. Gasto Nacional y Financiamiento del Sector dela Salud en América Latina y el Caribe: Desafíos para la Década de los Noventa. Washington, DC: OPS/ Organización Mundial de la Salud.

OPS (Organización Panamericana de la Salud), 1998. La Salud en las Américas. Washington, DC: OPS.

OPS (Organización Panamericana de la Salud), 1999. Disparidades de Salud en América Latina y el Caribe. Washington, DC: División de Salud y Desarrollo Humano, OPS

OPS (Organización Panamericana de la Salud), 2000. Base de Datos. Washington, DC: Programa de Salud y Desarrollo Humano, División de Salud y De- sarrollo Humano, Organización Panamericana de la Salud. (mimeo.)

OPS (Organización Panamericana de la Salud)/CEPAL (Comisión Económica para América Latina y el Caribe), 1994. Salud, Equidad y Transformación Productiva en América Latina y Caribe. Serie Documentos Reproducidos 41. Washington, DC: OPS.

PAALMAN, M.; BEKEDAM, H.; HAWKEN, L. \& NYHEIM, D., 1998. A critical review of priority setting in the health sector: The methodology of the 1993 World Development Report. Health Policy and Planning, 13:13-31.

PNUD (Programa de las Nacionales Unidas para el Desarrollo), 2001. Relatorio del Desarrollo Humano, 2001. Washington, DC: Naciones Unidas.

SANTOS, W. G., 1998. A trágica condição da política social. In: Política Social e Combateà Pobreza (S. H. Abranches, W. G. Santos \& M. A. Coimbra, org.), pp. 33-64, Rio de Janeiro: Jorge Zahar Editor.

SANTOS, W. G., 1979. Cidadania e Justiça. Rio de Janeiro: Editora Campus.

SCHIEBER, G. \& MAEDA, A, 1999. Health care financing and delivery in developing countries. Health Affairs, 18:193-205.

SOJO, A., 1998. Los compromisos de gestión en salud en Costa Rica com una perspectiva comparativa. Revista dela CEPAL, 66:73-103.

SOJO, A., 2001. Reformas de gestión en salud en América Latina. Revista dela CEPAL, 74:139-157.

SUAREZ-BERENGUELA, R., 2000. Health Inequalities in Latin America and the Caribbean: Findings and Policy Implication. Working Document. Washington, DC: Pan American Health Organization/World Bank.

SZÉKELY, M., 2001. The 1990s in Latin America: Another Decade of Persistent Inequality, but with Some what Lower Poverty. Working Paper 454. Washington, DC: Inter-American Development Bank.

van der HOEVEN, R. \& STEWART, F., 1993. Social Development During Periods of Structural Adjustment in Latin America. Occasional Paper 18. Geneva: International Labour Office. (mimeo.)

WHO (World Health Organization), 1996. Equity in Health and Health Care: A WHO/SIDA Initiative. Genebra: WHO.

WHO (World Health Organization), 2000. World Health Report, 2000. Genebra: WHO.

WORLD BANK, 1990. Social Spending in Latin America: The Story of the 1980s. Report 8450. Washington, DC: Technical Department Latin America and the Caribbean Region Regional Office, World Bank.

WORLD BANK, 1993a. Poverty and Income Distribution in Latin America: The Story of the 1980s. Washington, DC: Technical Department Latin America and the Caribbean Region Regional Office, World Bank.

WORLD BANK, 1993b. Implementing the Bank's Strategy to Reduce Poverty. Washington, DC: World Bank.

WORLD BANK, 1993c. World Development Report: Investing in Health. Washington, DC: World Bank.

Recibido el 17 de diciembre de 2001

Versión final presentada el 10 de marzo de 2001

Aprobado el 2 de abril de 2001 